\title{
Research of the PPP Financing Model in Supporting the Infrastructure Construction of "The Belt and Road"
}

\author{
Qihua Yin \\ School of Economics and Management, Southeast University, China
}

\begin{abstract}
Nowadays, Strengthening regional and global cooperation is a necessary condition for promoting the development of world economy and it is becoming an unstoppable trend. In The Belt and Road strategy advocated by our country, the growing demand for financing for public goods, represented by infrastructure, has been curbed. This is extremely detrimental to the success of The Belt and Road strategy in countries along the route. In view of this, the investment and financing model of infrastructure construction, which was completely government-led, must be reformed. The PPP model, as the innovative financing model, has become the important direction of the Belt and Road infrastructure investment and financing reform. This essay first discusses the present situation and predicament of the national infrastructure along the Belt and Road. Then summarizes The PPP financing model in support of the "The Belt and Road" infrastructure construction, the method of PPP financing is proposed to support the path selection in the infrastructure construction of The Belt and Road. Finally, the method of PPP financing is proposed to support the path selection in the infrastructure construction of The Belt and Road, trying to provide policy advice for the smooth implementation of The Belt and Road strategy.
\end{abstract}

Keywords: the Belt and Road, PPP financing model, infrastructure construction, function.

\section{Introduction}

\subsection{The Definition of " The Belt and Road " and Infrastructure}

"The Belt and Road" is the abbreviation of "the Silk Road Economic Zone" and "the 21st century Sea Silk Road". It has actively developed the economic partnership between land and sea routes along the Silk Road through the existing dual multilateral mechanism and regional cooperation platform and borrowed the historical symbols of the ancient Silk Road, an attempt to forge political mutual trust and economic integration and a highly inclusive community of interests, aimed at achieving new normality in the peaceful development of access, navigation and trade in all countries of the world, is highly inclusive, that is, where willing countries and economies can join in the community of interests, The scope of cooperation includes, but is not limited to, transport infrastructure, energy cooperation, international trade and investment. "The Belt and Road " is conducive to translate the advantages of political trust and mutual complements in economy into pragmatic cooperation, an open and inclusive economic cooperation initiative, not a concrete entity. China and Silk Road countries along the way to share high-quality production capacity, to discuss the project investment and share the results of cooperation, including road jointing, trade unblocked, currency, policy communication, the hearts and minds and so on, which aims to achieve the following mission: to explore the road to economic growth; to achieve globalization and global balancing; to create new regional cooperation. Infrastructure is the physical engineering facilities that based on the provision of public services to to meet social production and the life of the population, thereby guaranteeing the national or regional social and economic activities of the public service system. 


\subsection{PPP Financing Model Definition and Characteristics}

PPP model (Public Private Partnership) is to provide some public goods and services, on the basis of the franchise agreement, form a partnership between the government and private organizations relations of cooperation, and to clear the rights and obligations of both sides in the contract, make the parties reach alone more favorable results than expected. PPP model of government-departments and private capital can make full use of their respective advantages than expected alone, which is to integrate the government's vision plan with the capital and management efficiency of private capital.

PPP model is not only reasonable risk distribution, but also promotes the diversification of investment subject. Private sector assets and service capabilities can provide more money and skills for government departments to promote the government investment and financing system reform. Private sector participation in the PPP project can promote the construction in the project design, facilities. The management process and other aspects of innovation, improve the effectiveness and efficiency of the whole process of the project. The government and the private sector can play the advantages of the government public institutions and private institutions respectively, make up for their lack of long-term goals. They can form mutually beneficial goals; can be the most cost effective for the community to provide high quality services to the public.

\subsection{The Role of Infrastructure Construction in " The Belt and Road "}

As mentioned above, infrastructure can provide material engineering facilities for social production and residential life, which ensures the normal functioning of social and economic activities in the country or region. It has a "multiplier effect", which can bring a number of times based on social aggregate demand and national income investment. The improvement of the infrastructure can be used as an important basis to judge the sustainable and stable development of society, and also the basic condition for the interconnection of the countries along the construction line, which is due to the improvement of the infrastructure in the area along the joint. In essence, infrastructure construction is the cornerstone of the strategic development of "The Belt and Road ", which plays an important role in the economic and social development.

The country and region along the "The Belt and Road " cover nearly 5 billion people, accounting for about $70 \%$ of the global population, and the economy is about $\$ 39$ trillion trillion, or about $52 \%$ of the world's total. The backwardness of infrastructure and investment expenditure of infrastructure in the country and region along the line are generally rigid financial constraints. At the same time, the density of railways and highways along China's borders lags far behind the national average, and the demand gap of infrastructure are larger. Infrastructure construction relies entirely on government investment may not be realized, nor can it be provided entirely by social capital. The use of Public-Private Partnership not only can make up for funding gap, but also is in line with the principle of sharing interest and risk, which can better meet the " The Belt and Road " construction project funds demand. Therefore, the study of Public-Private Partnership, in support of "The Belt and Road " infrastructure constructions function, can better serve the "The Belt and Road " strategy landing.

\section{The Present Situation and Difficulties of the Belt and Road Along the Country's Infrastructure}

\section{1. "The Belt and Road along the Country's Infrastructure Status"}

The Belt and Road along involving a total of 65 countries and regions, the area of about 54 million square kilometers, accounting for $40 \%$ of the global land area has a population of about 4 billion 600 million; the total global population, $62.8 \%$ of the total, but along the national infrastructure overall level of development in the middle level, only Israel and other three countries at a high level, the Singapore ranked first; there are 26 countries in the "high" level, accounting for 40.63\%, 21 countries in the "middle" level, accounting for about $32.81 \%, 13$ the country is at a low level, accounting for $20.31 \% ; 1$ countries in the "low" level, accounting for $1.56 \%$. 


\subsection{The Infrastructure Construction of Countries along The Belt and Road is in Trouble}

As the global economic recovery has been sluggish, there has been an increase in uncertainty over economic development. Many government hopes to strengthen the construction of infrastructure to create a new driving force for economic development, but the government cannot meet the demand for investment is too large. Bilateral and multilateral cooperation mechanisms is difficult to effectively build facilities, this is due to the relevant countries along more about their own interests, cross-border cooperation in infrastructure is still in the exploratory stage, and infrastructure construction is lack of lasting profitable mode, cannot form a stable cash flow. The developed countries are more concerned about the infrastructure obsolete and upgrading, while developing countries urgently to compensate for the huge infrastructure supply gap. The country market level difference along The Belt and Road is bigger; the government's fund-raising ability is also different. There are obvious differences in the political system, economic and social system, development degree, legal system, policy system and religious culture among the countries along the way, which have caused the difficulty of infrastructure construction

\section{The Functions and Effect of PPP Model in "The Belt and Road" Infrastructure Construction}

\subsection{To Raise the Financing Capacity of Governments along The Belt and Road}

The PPP model is an innovative way of financing public goods and services that are both marketable and socialized ,it can unleash the vitality of social capital and alleviate the financial pressure of relevant governments, make up for the lack of government investment. This is because the PPP model has a good advantage in integrating global capital and integrating idle social capital. On the basis of improving the financing capacity of governments along the belt and road, we will improve the efficiency and quality of government investment and reduce the amount of government debt. The risks in infrastructure design and construction can be effectively reduced.

\subsection{Enhance the Design, Construction, Financing, Maintenance and Operation of Infrastructure Projects}

The private sector is more experienced in the design, construction, financing, maintenance and operation of infrastructure projects. At the same time, the private sector operates more flexibly than the government, can better adapt to the international cross-border capital operation, especially in the countries along the infrastructure of the design, construction, financing, maintenance, and operations more professional.

\subsection{Strengthen the Fit Degree of the Advantages of Countries Along the Belt and Road}

The countries along the Belt and Road have different infrastructure, A country may not be able to achieve the optimal Pareto level of infrastructure, We need to effectively integrate national strengths and reinforce the complementary strengths of countries along the belt and road. The PPP model can be achieved in this respect, and cooperation can be established as a carrier for the cooperation of relevant parties.

\section{The Path Selection of Public-Private Partnership Supporting the "The Belt and Road" Infrastructure}

\subsection{Jointly Develop Efficient Financing Products and Financial Instruments}

Firstly, national financial institutions should strengthen cooperation, design profitable financing projects and products, give full play to the role of financing products and services in infrastructure construction. From the point of view of financing project, the project Bank of Public-Private Partnership along the "The Belt and Road" can be set up in accordance with the actual demand of each country, for private capital to participate in the construction of cross-border infrastructure. Secondly, securitize the Cross-border infrastructure which is financed by the issuance of bonds on the basis of cross-border infrastructure gains. Finally, the establishment of "the Belt and Road " Cross-border infrastructure stock Exchange, for the national private capital to participate in 
" The Belt and Road " Cross-border infrastructure investment to provide investment platform for the implementation of Public-Private Partnership to create a better financing environment.

\subsection{Spread and Transfer Project Investment Risk Through Public-Private Partnership Insurance Protocol}

In support of the "The Belt and Road " infrastructure construction, through the Public-Private Partnership financing is huge, associated with the interest rate risk, exchange rate risk and inflation risk will have a certain impact on corporate profits, that is, financial risk and economic risk will have a greater impact on the PublicPrivate Partnership project costs. The enterprise may disperse and transfer the investment risk of the project through the related agreement, especially through the Public-Private Partnership Insurance agreement can reasonably distribute the risk, clear the relevant partner's right and obligation relations, adhering to the principle that the most suitable risk control party undertakes the risk.

\subsection{Improve the Legal Framework to Provide Institutional Guarantee for Innovation in Investment and Financing Models}

Countries along the Belt and Road should be actively involved in the formulation of international rules, host governments, not only need to strengthen the country's law construction and the need to emphasis on the importance of cooperation with it the law of the state. This is due to the level of all countries in the world of the rule of law and the rule of law framework difference is bigger, in the implementation of the PPP project investment and financing cooperation of the government by law must be put through to the protection of the rights of all partners, through the equalization of fulfillment to achieve the interests of all parties. In addition, the private sectors of the PPP model form partnerships with the public sector of the government and keep the project objectives consistent. Only the PPP financing program run the rule-of-law level of ascension, to make the social capital has the stable expectations, so the perfect legal framework can provide a system guarantee for the investment and financing mode innovation.

\subsection{Avoid Financing Risks and Credit Risks}

Using the PPP mode of operation of public infrastructure construction project investment is huge, leverage ratio is higher, and project financial earnings stability is poorer, financing risk and credit risk is higher. Therefore, for the PPP project should carry on the effective risk identification and risk assessment; strengthen the whole process of the PPP project risk management, so as to realize the limited controls the PPP project financing risk and credit risk. Only effective regulation of financing risk and credit risk will attract more social capital to participate in the "The Belt and Road" infrastructure construction.

\section{Concluding Remarks}

Infrastructure construction has important practical significance for the smooth implementation of the "The Belt and Road" strategy, and the larger funding gap has become a bottleneck restricting the development of The Belt and Road along the country's infrastructure construction projects. Therefore, we must explore the role and function of the PPP financing model in supporting the infrastructure construction of the Belt And Road, which should not be underestimated. The PPP financing model can improve the financing capacity of governments along the route and it also can enhance the design, infrastructure construction, financing, operation and maintenance capabilities of infrastructure projects, and to strengthen the complementary fit along the route. In the choice of path to explore the financing mode of PPP in supporting "The Belt and Road "infrastructure construction, we can choose to start with the development of financing products, avoiding risks or providing system security perspective. 


\section{References}

[1] C.R. Martell ,and G.M. Guess, "Development of local government debt financing markets: application of a marketbased framework," Public Budgeting\& Finance, Vol. 26 ,pp. 88-119, January 2016.

[2] A. Sadeghi, O. Barati , P. Bastani , D. Daneshjafari and M. Etemadian , "Strategies to develop and promote publicprivate partnerships (PPPs) in the provision of hospital services in Iran: a qualitative study," Electronic Physician, Vol. 8 ,pp2208-2214, August 2016.

[3] M Łakomy-Zinowik , "Public-private partnership as an alternative source of financing of public tasks," Ekonomiai Prawo, Vol. 16,pp75-86, January 2017.

[4] HP Hilmarsson, "Public-Private Partnerships for clean energy investment in developing and emerging economies: Allocating risks and sharing rewards," Theoretical \& Applied Economics, Vol. 24,pp147-160, February 2017

[5] M.S. Tahir,“ Public private partnerships (PPPs); innovations and improvements for future: health care systems in Pakistan,” Professional Medical Journal, ,Vol. 24 ,pp1-9, January 2017.

[6] Zeneli, Fjona. Between Public - Private Partnerships and public finance in the public infrastructure sector: The water and sanitation sector in Albania," Academic Journal of Business, Administration, Law \& Social Sciences,2017, Vol. 3 Issue 1, pp205-212.

[7] R. A .Gilemkhanov, ,S. Y Lukichev, L. U.Drobina,,and N. V . Braila “"Effective models of public-private partnership in municipal facilities ," Construction of Unique Buildings \& Structures, Vol. 53, pp78-86,February 2017.

[8] T Hang ,D Thi "“ Evaluating the decision-making on a Public-Private Partnership to finance a road project in Vietnam,” Journal of International Studies,Vol. 9 ,pp124-137,March 2016. 